CLINICAL STUDY

\title{
Increased prevalence of subclinical cardiac valve fibrosis in patients with prolactinomas on long-term bromocriptine and cabergoline treatment
}

\author{
Atanaska Elenkova $^{1}$, Rabhat Shabani ${ }^{2}$, Krassimir Kalinov $^{3}$ and Sabina Zacharieva ${ }^{1}$ \\ ${ }^{1}$ Clinical Centre of Endocrinology, USHATE 'Acad.Ivan Pentchev' and ${ }^{2}$ Department of Internal Medicine, UMHAT 'Alexandrovska', Medical University, \\ Sofia, Bulgaria and ${ }^{3}$ Department of Informatics, New Bulgarian University, Sofia, Bulgaria \\ (Correspondence should be addressed to A Elenkova; Email: atanaskae@yahoo.com)
}

\begin{abstract}
Background: In contrast to cabergoline, evidence-based information about a possible profibrotic effect of bromocriptine in prolactinoma patients is extremely limited.

Objective: To assess the prevalence of valvular lesions among patients on long-term bromocriptine or cabergoline therapy.

Design: Case-control study.

Methods: A transthoracic echocardiographic evaluation was performed in 334 subjects divided into four groups: 103 cabergoline treated, 55 bromocriptine treated, 74 naïve patients, and 102 controls. Results: Clinically relevant valve regurgitations were equally prevalent in all investigated groups whereas subclinical valve fibrosis was significantly more frequent in both bromocriptine- and cabergoline-treated patients ( 40 vs 43.6 vs 21.6 vs $23.5 \% ; P=0.004$ ). The odds ratio $(\mathrm{OR}$ ) for developing valvular fibrosis was 2.27 (95\% CI 1.17-4.41; $P=0.016)$ for cabergoline and 2.66 (95\% CI $1.22-5.78 ; P=0.014$ ) for bromocriptine groups compared with subjects not exposed to dopamine agonists (DAs). A significantly higher pulmonary arterial pressure corresponding to the longer treatment duration was observed among patients taking bromocriptine compared with cabergolinetreated subjects.

Conclusions: Long-term treatment with cabergoline and bromocriptine seems not to be associated with an increased risk of clinically significant valve disease but possible subclinical lesions should be expected. An echocardiographic examination is recommended at the beginning and periodically during therapy with DAs acting as full or partial agonists of 5-hydroxytrytamine 2B receptors (cabergoline and bromocriptine). Bromocriptine seems not to be a safe alternative for patients receiving cabergoline treatment who have preexisting or diagnosed abnormalities suggesting valvular, interstitial myocardial, or pulmonary fibrosis. Further studies are needed to investigate the possible impact of DA treatment on pulmonary arterial pressure.
\end{abstract}

European Journal of Endocrinology 167 17-25

\section{Introduction}

Several cross-sectional studies have demonstrated a significantly increased risk of valvular fibrosis in Parkinson's patients treated with the ergot-derived dopamine agonists (DAs) pergolide and cabergoline $(1,2,3,4,5,6)$. Extensive research over the last decade has highlighted the crucial role of 5-hydroxytryptamine 2B receptors (HTR2B) in the pathogenesis of this fibrotic valvular heart disease (FVHD) (7). Agonism of HTR2B is not a class effect of the ergolines: pergolide and cabergoline have been shown to exert full agonistic activity whereas lisuride and terguride are potent HTR2B antagonists $(8,9)$. As ergot-derived DAs represent the first-line agents for the management of prolactinomas, the risk of FVHD in patients on longterm cabergoline treatment has been one of the current 'hot topics' in endocrine research. In contrast, evidencebased information about a possible profibrotic effect of bromocriptine is extremely limited. Although numerous cases of bromocriptine-associated fibrosis have been reported in the literature, only two studies have provided data on the prevalence of valve regurgitations in bromocriptine-treated patients with Parkinson's disease $(10,11,12,13,14)$. Even less is known about the long-term bromocriptine cardiovascular safety in patients with prolactinomas. To date, results of only one very small case-control study comprising a separate group of 19 bromocriptine-treated patients have been published (15). 


\section{Materials and methods}

\section{Study design}

This observational case-control study was conducted as part of a scientific research project approved by the Central Committee on Research Ethics at the Bulgarian Ministry of Education and Science. The primary objective was to investigate the prevalence of FVHD among patients on long-term bromocriptine therapy compared with cabergoline-treated subjects, medically naïve patients, and healthy controls. In a prospective design from May 2008 to October 2011, a total number of 424 candidates were screened, of whom 338 subjects were recruited. Study participants were enrolled into four groups: group A consisted of 105 patients with prolactinomas taking cabergoline; group B of 57 patients on bromocriptine therapy; group $\mathrm{C}$ of 74 newly diagnosed medically naïve patients; and group $\mathrm{D}$ of 102 control subjects, recruited among medical staff and their acquaintances. Inclusion criteria for groups A, $\mathrm{B}$, and C: diagnosis of prolactinoma based on current guidelines; for groups A and B: treatment with one DA for at least 12 months before the study; for group D: control group frequency-matched for age, sex, obesity, and arterial hypertension. Exclusion criteria were: i) severe, untreated, or uncontrolled arterial hypertension; ii) ischemic heart disease (all forms); iii) history of previous or concomitant cardiac disease with a substantial risk of heart damage such as myocarditis, pericarditis, rheumatism, connective tissue diseases, and hyperthyroidism; iv) current or previous use of drugs with potential profibrotic effects on heart valves; v) use of more than one DA for treatment of prolactinoma; vi) hyperprolactinemia of nontumoral origin; vii) cosecretion of prolactin and GH (somatoprolactinomas); and viii) Parkinson's disease. The screen failure rate was $39 \%$ (86 patients) and was mainly determined by the great number of patients switched from one DA to another. Four participants were excluded from the study: two cabergoline-treated males because of unstable angina, one patient taking bromocriptine with moderate tricuspid regurgitation and a history of rheumatic fever (data were provided by the patient after performing the study procedures), and one young woman on bromocriptine therapy with suspected bicuspid aortic valve who refused the confirmatory transesophageal echocardiography. Data of 334 participants (study completers) were analyzed: 103 cabergoline treated, 55 bromocriptine taking, 74 de novo patients, and 102 healthy controls.

\section{Study procedures}

Study procedures were performed after signing a specific informed consent by participants and study investigators.
Patient history Data about tumor size, prolactin levels at diagnosis and study entry, treatment duration, initial and therapeutic dose of DA, previous and concomitant diseases, and medication were collected.

Anthropometric parameters Height, weight, and blood pressure (BP) were measured in all the study participants. Arterial hypertension was defined as elevated arterial BP, with systolic pressure over $140 \mathrm{~mm} \mathrm{Hg}$ and/or diastolic pressure over $90 \mathrm{~mm} \mathrm{Hg}$ at the time of diagnosis according to the Joint National Committee on Prevention, Detection, Evaluation, and Treatment of High Blood Pressure (16). Body surface area (BSA) was calculated using the Mosteller formula (17). Office BP was measured in standard fashion with the patient sitting for $5 \mathrm{~min}$. Three measurements were taken and averaged to give the office BP used in this analysis.

Echocardiography A transthoracic M-mode and twodimensional, with pulsed wave (PW), continuous wave (CW) and Color Doppler echocardiography was performed in all investigated subjects by one experienced cardiologistechocardiographer who was blind to the study participants' data. All echocardiograms were performed using Toshiba Power Vision 6000 Ultrasound machine. Severity of mitral, aortic, and tricuspid regurgitation was categorized according to the recommendations of the American Society of Echocardiography as follows: none (grade 0), trace (grade 1), mild (grade 2), moderate (grade 3), and severe (grade 4) (18). Pulmonary regurgitation (PR) was graded as mild, moderate, or severe by using two different methods based on color flow imaging according to the current guidelines of the European Association of Echocardiography (19). In order to avoid false-positive results, PR of grade 1 (trace) was not taken into consideration. Valve regurgitation of at least grade 2 for the aortic valve and grade 3 or 4 for mitral, tricuspid, or pulmonary valves was considered clinically significant (18). In case of tricuspid regurgitation, systolic pulmonary arterial pressure (PAPS) was estimated using the modified Bernoulli equation. Mean pulmonary pressure (mPAP) was calculated using the following formula: $\mathrm{mPAP}=0.61 \times \mathrm{PAPS}+$ $2 \mathrm{~mm} \mathrm{Hg} \mathrm{(20).} \mathrm{Pulmonary} \mathrm{hypertension} \mathrm{was} \mathrm{defined} \mathrm{by}$ systolic and mean pulmonary artery pressures of more than 40 and $25 \mathrm{mmHg}$ respectively. The following parameters were measured on M-mode tracing: endsystolic and end-diastolic interventricular septum thickness systole (IVSTS and IVSTD), left ventricular internal end-systolic and end-diastolic diameters (LVIDS and LVIDD), and posterior wall thickness in systole and diastole (PWTS and PWTD). Left atrium (LA) diameter, maximum aortic diameter (AO), end-diastolic volume (EDV), endsystolic volume (ESV), and stroke volume (SV) presented as indices $(\mathrm{Xi}=\mathrm{X} / \mathrm{BSA})$ were also compared between investigated study groups. Left ventricular mass indexed for BSA (LVMi) was calculated by Penn cube method according to Devereux's formula: LVMi $\left(\mathrm{g} / \mathrm{m}^{2}\right)=(1.04 \times($ IVST $+\mathrm{LVID}+\mathrm{PWT}) 3-(\mathrm{LVID}) 3-13.6) / \mathrm{BSA} \quad$ (21). LVMi 
$\geq 110 \mathrm{~g} / \mathrm{m}^{2}$ in women and $\geq 134 \mathrm{~g} / \mathrm{m}^{2}$ in men were accepted as cutoff points for left ventricular hypertrophy (21). Assessment of the left ventricular systolic function was mainly based on the ejection fraction (EF) and shortening fraction (EFS) with normal values respectively: $\mathrm{EF}>50 \%$ and EFS from 30 to $45 \%$. Diastolic function of the left ventricle was assessed by isovolumic relaxation time (IVRT) and deceleration time (DTE). Values of IVRT over $100 \mathrm{~ms}$ and DTE over $240 \mathrm{~ms}$ indicated impaired left ventricular relaxation. Restrictive transmitral filling was considered present when DTE was $\leq 140$ ms. Structural abnormalities of valvular cusps and annuluses were also evaluated using cross-sectional echocardiogram. Subclinical valvular fibrosis (SCVF) was defined as fibrosis (with or without calcification) not accompanied by regurgitation of any degree. SCVF was considered present in all cases with increased echogenicity (hyperechogenicity) and thickness of valvular cusps ( $>3 \mathrm{~mm}$ for mitral valve; $>2 \mathrm{~mm}$ for aortic, tricuspid, and pulmonic valves). Mitral valve prolapse (MVP) was defined as abnormal systolic valve movement of one or both mitral leaflets toward the LA ( $\geq 2 \mathrm{~mm}$ beyond the annular plane). Based on the thickness $(d)$ of the mitral valve leaflets, MVP was classified as nonclassic $(d \leq 5 \mathrm{~mm})$ and classic $(d>5 \mathrm{~mm})$ subtypes.

Assay methods Serum prolactin concentrations at study entry were measured by RIA (PRL-IRMA Kit, DIAsource Immunoassays, Belgium) with an analytical sensitivity $<0.35 \mathrm{ng} / \mathrm{ml}(10.15 \mathrm{mIU} / \mathrm{l})$ and detection range 10.15-3857 mIU/l. The intra- and interassay coefficients of variation were 5.2 and $4.5 \%$ respectively. The reference intervals for males were 52.2-561.1 mIU/l; for premenopausal women: 78.3-571.3 mIU/l; and for postmenopausal women: 55.1-519.1 mIU/l.

\section{Statistical analysis}

The following statistical methods were used for data description and statistical inferences.
Descriptive methods Metric variables were described by $n$ (number of observations), arithmetic mean, s.D., and range (minimum and maximum). Nonmetric variables were described by $n$ (number of observations) and relative frequency distribution (in percentage).

Methods for statistical inference One-way ANOVA was applied in the case of more than two groups. Multiple post hoc comparisons were made according to the Student-Newman-Keuls approach. Student's $t$-test was used when there were two groups. The hypotheses about nonmetric variables were tested by $\chi^{2}$ test. Where possible, the Fisher's exact observed significance level was calculated. Kruskal-Wallis and Mann-Whitney nonparametric tests were used as an addition to parametric ANOVA and t-test. Pearson's correlation coefficient $r$ and $\eta$ coefficient were used to discover the relationships between variables. The decision was accepted to reject the null hypothesis (of no difference) if the observed significance $(P$ value $)$ was $<0.05$ (significance level).

\section{Results}

The clinical characteristics of study participants are summarized in Table 1. Investigated groups did not differ by age, BMI, BSA, and systolic blood pressure and diastolic blood pressure. All the three patient groups had comparable percentages of subjects with arterial hypertension, macroadenomas, and hypopituitarism. Patients taking bromocriptine had significantly longer treatment duration compared with cabergoline-treated subjects $(58.98 \pm 47.03$ vs $46.5 \pm 27.6$ months; $P=0.037)$.

The main parameters obtained by transthoracic echocardiography are depicted in Table 2. StudentNewman-Keuls post hoc analysis revealed a significantly higher IVSTD in bromocriptine- and cabergoline-treated patients compared with de novo patients and healthy

Table 1 Clinical characteristics of study subjects (data are expressed as mean \pm s.D.).

\begin{tabular}{|c|c|c|c|c|c|}
\hline & $\begin{array}{l}\text { Group A, } \\
\text { cabergoline }\end{array}$ & $\begin{array}{l}\text { Group B, } \\
\text { bromocriptine }\end{array}$ & $\begin{array}{l}\text { Group } C \text {, } \\
\text { naïve patients }\end{array}$ & $\begin{array}{l}\text { Group D, } \\
\text { healthy subjects }\end{array}$ & $\boldsymbol{P}$ \\
\hline$n$ & 103 & 55 & 74 & 102 & \\
\hline Women/men & $82 / 21$ & $44 / 11$ & $58 / 16$ & $81 / 21$ & 0.997 \\
\hline Age (years) & $38.6 \pm 9.93$ & $39.1 \pm 11.3$ & $35.0 \pm 9.85$ & $38.0 \pm 9.65$ & 0.072 \\
\hline Macroprolactinomas (n(\%)) & $31(30.1)$ & $16(29.1)$ & $22(29.8)$ & - & 1.000 \\
\hline Arterial hypertension $(n(\%))$ & $15(14.6)$ & $9(16.4)$ & $11(14.9)$ & $15(14.7)$ & 0.994 \\
\hline $\mathrm{SBP}(\mathrm{mm} \mathrm{Hg})$ & $119.2 \pm 10.5$ & $122.4 \pm 11.4$ & $120.8 \pm 9.37$ & $122.0 \pm 7.90$ & 0.106 \\
\hline DBP (mm Hg) & $76.3 \pm 6.59$ & $78.2 \pm 7.52$ & $77.2 \pm 7.09$ & $75.4 \pm 5.14$ & 0.419 \\
\hline BMI $\left(\mathrm{kg} / \mathrm{m}^{2}\right)$ & $26.1 \pm 6.60$ & $26.6 \pm 6.20$ & $26.3 \pm 6.37$ & $26.0 \pm 6.42$ & 0.944 \\
\hline $\operatorname{BSA}\left(\mathrm{m}^{2}\right)$ & $1.90 \pm 0.27$ & $1.91 \pm 0.27$ & $1.92 \pm 0.29$ & $1.89 \pm 0.26$ & 0.991 \\
\hline Hypopituitarism (n (\%)) & $7(12.7)$ & $14(13.6)$ & $10(13.5)$ & - & 1.000 \\
\hline sPRL levels at study entry (mIU/l) & $583.9 \pm 1040.6$ & $841.9 \pm 978.22$ & $6474.86 \pm 16384.8$ & $353.4 \pm 187.04$ & $<0.001$ \\
\hline Treatment duration (range, $\mathrm{m}$ ) & $46.5 \pm 27.6(12-128)$ & $58.98 \pm 47.03(12-240)$ & - & - & 0.037 \\
\hline CD (range, mg) & $173.9(24-1322)$ & 9427491 (900-45 000) & - & - & \\
\hline
\end{tabular}

SBP, systolic blood pressure; DBP, diastolic blood pressure; BMI, body mass index; BSA, body surface area; CD, cumulative dose. 
Table 2 Echocardiographic parameters of patients and healthy controls (data are expressed as mean \pm s.D.).

\begin{tabular}{lllll}
\hline & $\begin{array}{l}\text { Group A, } \\
\text { cabergoline }\end{array}$ & $\begin{array}{l}\text { Group B, } \\
\text { bromocriptine }\end{array}$ & $\begin{array}{l}\text { Group C, } \\
\text { naïve patients }\end{array}$ & $\begin{array}{l}\text { Group D, } \\
\text { healthy subjects }\end{array}$ \\
\hline$n$ & 103 & 55 & 74 & 102 \\
LVIDS $(\mathrm{mm})$ & $27.4 \pm 4.67$ & $28.4 \pm 6.1$ & $27.5 \pm 5.09$ & $27.7 \pm 6.06$ \\
LVIDD $(\mathrm{mm})$ & $44.1 \pm 4.62$ & $44.9 \pm 5.19$ & $44.0 \pm 5.79$ & $44.6 \pm 4.53$ \\
IVSTS $(\mathrm{mm})$ & $13.5 \pm 1.85$ & $13.8 \pm 2.13$ & $13.5 \pm 2.00$ & $13.6 \pm 1.37$ \\
IVSTD $(\mathrm{mm})$ & $9.49 \pm 1.81$ & $10.0 \pm 1.88$ & $9.28 \pm 1.60$ & $9.19 \pm 1.43$ \\
PWTS $(\mathrm{mm})$ & $14.7 \pm 2.65$ & $15.1 \pm 4.14$ & $14.4 \pm 2.16$ & $14.5 \pm 1.84$ \\
PWTD $(\mathrm{mm})$ & $9.60 \pm 1.73$ & $9.72 \pm 1.85$ & $9.23 \pm 1.43$ & $9.31 \pm 1.25$ \\
LAi $\left(\mathrm{mm} / \mathrm{m}^{2}\right)$ & $18.5 \pm 2.44$ & $18.4 \pm 2.68$ & $17.8 \pm 2.22$ & $17.9 \pm 2.13$ \\
LVM $\left(\mathrm{g} / \mathrm{m}^{2}\right)$ & $97.4 \pm 24.9$ & $104.5 \pm 30.4$ & $93.1 \pm 24.1$ & $95.1 \pm 20.9$ \\
AOi $\left(\mathrm{mm} / \mathrm{m}^{2}\right)$ & $16.5 \pm 2.34$ & $16.9 \pm 2.59$ & $16.2 \pm 2.14$ & $16.2 \pm 2.23$ \\
EF $(\%)$ & $68.3 \pm 7.87$ & $67.7 \pm 7.14$ & $67.9 \pm 8.61$ & $69.5 \pm 6.84$ \\
FS $(\%)$ & $38.2 \pm 6.37$ & $38.4 \pm 5.17$ & $37.9 \pm 6.32$ & $39.4 \pm 5.51$ \\
DTE $(\mathrm{ms})$ & $165.4 \pm 28.81$ & $172.7 \pm 34.98$ & $167.8 \pm 36.26$ & $163.9 \pm 22.62$ \\
IVRT $(\mathrm{ms})$ & $87.3 \pm 13.44$ & $93.36 \pm 19.29$ & $89.32 \pm 19.59$ & $83.95 \pm 8.38$ \\
EDVi $\left(\mathrm{ml} / \mathrm{m}^{2}\right)$ & $52.1 \pm 11.63$ & $53.5 \pm 13.06$ & $49.4 \pm 10.73$ & $51.4 \pm 10.27$ \\
ESVi $\left(\mathrm{ml} / \mathrm{m}^{2}\right)$ & $16.6 \pm 5.14$ & $17.3 \pm 5.78$ & $15.9 \pm 4.63$ & $15.6 \pm 4.37$ \\
SVi $\left(\mathrm{ml} / \mathrm{m}^{2}\right)$ & $35.5 \pm 9.09$ & $36.1 \pm 9.70$ & $33.5 \pm 8.44$ & 0.027 \\
PAPS $(\mathrm{mm} \mathrm{Hg})$ & $25.56 \pm 4.41(n=60)$ & $27.93 \pm 4.50(n=37)$ & $24.93 \pm 4.33(n=34)$ & $25.55 \pm 4.44(n=53)$ \\
$\mathrm{mPAP}(\mathrm{mm} \mathrm{Hg})$ & $17.6 \pm 2.69(n=60)$ & $19.0 \pm 2.74(n=37)$ & $17.2 \pm 2.64(n=37)$ & $17.6 \pm 2.71(n=53)$ \\
\hline
\end{tabular}

IVSTD, interventricular septum thickness diastole; IVSTS, interventricular septum thickness systole; PWTD, posterior wall thickness diastole; PWTS, posterior wall thickness systole; LVMi, left ventricular mass index; EF, ejection fraction; EFS, ejection fractional shortening; IVRT, isovolumic relaxation time; DTE, deceleration time; LA, left atrium; AO, maximum aortic diameter; EDV, end-diastolic volume; ESV, end-systolic volume; SV, stroke volume; PAPS, systolic pulmonary arterial pressure; mPAP, mean pulmonary arterial pressure.

controls $(P<0.05)$. This parameter was comparable between subjects not exposed to DAs (naïve patients vs healthy controls: $P=0.491)$. No differences were found in the other left ventricular and LA dimensions as well as the parameters related to left ventricular function between all investigated groups. LVMi was nonsignificantly higher in bromocriptine group in comparison with the other study groups $(104.5 \pm 30.4$ vs 97.4 \pm 24.9 vs $93.1 \pm 24.1$ vs $95.1 \pm 20.9 ; P=0.057)$. On the basis of additional analyses, we excluded the testosterone-induced cardiac hypertrophy in male subjects as a possible factor influencing LVM. None of the study participants were diagnosed with pulmonary hypertension even though significantly higher systolic (PAPS) and mean arterial pulmonary pressures (mPAP) as well as significantly prolonged IVRT were registered in bromocriptine-treated patients compared with the other study groups.

Data on the prevalence of cardiac valve lesions are presented in Table 3. Mitral regurgitation (MR) was equally prevalent in all investigated groups (27.2 vs 27.3 vs 24.3 vs $29.4 \% ; P=0.912$ ). None of the study participants were classified as having clinically relevant (moderate or severe) MR. MVP was detected in 5.1\% of patients $(n=12)$ and in $3.9 \%(n=4)$ of healthy subjects. In all registered cases, MVP was classified as nonclassic prolapse of one mitral leaflet and was not associated with clinically relevant regurgitation. No significant differences were found in the prevalence of aortic regurgitation (AR) between four study groups (5.8 vs 10.9 vs 4.1 vs $2 \% ; P=0.113)$. PR of more than trace degree (mild, grade 2) was detected in one woman on bromocriptine treatment. We did not find significant differences in the prevalence of either pathological or clinically significant regurgitations of the mitral, aortic, or pulmonary valves between investigated groups. Prevalence of tricuspid regurgitation (all grades) was comparable in all investigated groups ( 58.3 vs 67.3 vs 45.9 vs $52.0 \%$; $P=0.086$ ), but controversial results were obtained when the frequencies of only pathological regurgitations were analyzed: 3.9 vs 7.3 vs 5.4 vs $0 \%$; $P=0.079$ (Pearson's $\chi^{2}$ ); $P=0.029$ (Fisher's exact test). Paired comparisons revealed a significant difference between bromocriptine-treated and healthy subjects $(P=0.014)$ as well as a borderline significance between cabergoline-treated patients and healthy controls $(P=0.062)$.

Hemodynamically relevant regurgitations were observed in four study participants: three patients with mild AR (two cabergoline and one bromocriptine treated) and one newly diagnosed patient with moderate tricuspid regurgitation. Their main characteristics are shown in Table 4. Partial hypopituitarism (hypogonadism and hypothyroidism) was present in one patient and mild-to-moderate well-controlled arterial hypertension in three of them. All the four subjects were asymptomatic.

Statistically higher frequency of SCVF (with or without calcinosis) not accompanied by regurgitation was found in medically treated patients (cabergoline and bromocriptine) compared with de novo patients and healthy controls ( 40 vs 43.6 vs 21.6 vs $23.5 \%$; $P=0.004)$. Monovalvular involvement was observed in relatively small comparable proportions of subjects in all investigated groups (Table 3). In the majority of cases, there was bi- or trivalvular involvement, 
Table 3 Prevalence of valvular lesions in patients and healthy subjects.

\begin{tabular}{|c|c|c|c|c|c|c|}
\hline \multirow[b]{2}{*}{$n$} & \multirow{2}{*}{$\begin{array}{l}\begin{array}{l}\text { Group A, } \\
\text { cabergoline }\end{array} \\
103\end{array}$} & \multirow{2}{*}{$\begin{array}{l}\text { Group B, } \\
\text { bromocriptine } \\
55\end{array}$} & \multirow{2}{*}{$\begin{array}{l}\text { Group C, } \\
\text { naïve patients } \\
74\end{array}$} & \multirow{2}{*}{$\begin{array}{l}\text { Group D, } \\
\text { healthy subjects } \\
102\end{array}$} & \multicolumn{2}{|c|}{$P$} \\
\hline & & & & & Pearson's $\chi^{2}$ & $\begin{array}{l}\text { Fisher's } \\
\text { exact test }\end{array}$ \\
\hline MiR total \% $(n)$ & $27.2(28)$ & $27.3(15)$ & $24.3(18)$ & $29.4(30)$ & 0.909 & 0.912 \\
\hline Pathological regurgitations & $3.9(4)$ & $5.5(3)$ & $2.7(2)$ & $1(1)$ & 0.427 & 0.407 \\
\hline Clinically relevant regurgitations & $\varnothing$ & $\varnothing$ & $\varnothing$ & $\varnothing$ & & \\
\hline AoR total \% $(n)$ & $5.8(6)$ & $10.9(6)$ & $4.1(3)$ & $2(2)$ & 0.103 & 0.113 \\
\hline Pathological regurgitations & $2(2)$ & $3.6(2)$ & $\varnothing$ & $\varnothing$ & 0.106 & 0.106 \\
\hline Clinically relevant regurgitations ${ }^{a}$ & $2(2)$ & $1.8(1)$ & $\varnothing$ & $\varnothing$ & 0.344 & 0.344 \\
\hline \multicolumn{7}{|l|}{ PR total $\%(n)$} \\
\hline Pathological regurgitations & $\varnothing$ & $1.8(1)$ & $\varnothing$ & $\varnothing$ & 0.383 & 0.383 \\
\hline Clinically relevant regurgitations & $\varnothing$ & $\varnothing$ & $\varnothing$ & $\varnothing$ & & \\
\hline TR total \% $(n)$ & $58.3(60)$ & $67.3(37)$ & $45.9(34)$ & $52.0(53)$ & 0.086 & 0.086 \\
\hline Pathological regurgitations & $3.9(4)$ & $7.3(4)$ & $5.4(4)$ & $\varnothing$ & 0.079 & 0.029 \\
\hline Clinically relevant regurgitations ${ }^{\mathrm{b}}$ & $\varnothing$ & $\varnothing$ & $1.4(1)$ & $\varnothing$ & 0.384 & 0.384 \\
\hline $\begin{array}{l}\text { All hemodynamically relevant } \\
\text { regurgitations }(n, \%)\end{array}$ & $2(2)$ & $1.8(1)$ & $1.4(1)$ & $0(0)$ & 0.645 & 0.535 \\
\hline Subclinical valvular fibrosis $(n, \%)$ & $40(41)$ & $43.6(24)$ & $21.6(16)$ & $23.5(24)$ & 0.004 & 0.004 \\
\hline $\begin{array}{l}\text { Monovalvular involvement } \\
\text { (without regurgitation) }\end{array}$ & $3(3)$ & $3.6(2)$ & $2.7(2)$ & $4.9(5)$ & 0.847 & 0.894 \\
\hline $\begin{array}{l}\text { Bi- or trivalvular involvement } \\
\text { (with regurgitation of } 0-2 \text { valves) }\end{array}$ & $37(38)$ & $40(22)$ & $18.9(14)$ & $18.6(19)$ & 0.001 & 0.001 \\
\hline
\end{tabular}

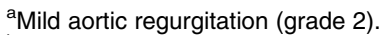

${ }^{\mathrm{b}}$ Moderate tricuspid regurgitation (grade 3 ).

i.e. coexistence of SCVF of one or two valves and trace or mild regurgitation of another valve(s). Fibrosis of more than one valve was twice as common in both groups of DA-treated patients than in de novo patients and healthy controls (Table 3). Hemodynamically relevant regurgitations were not registered among these subjects.

In addition, asymptomatic pericardial effusions (50 and $150 \mathrm{ml}$ respectively) were detected in two female patients treated with cabergoline and bromocriptine respectively.

Logistic regression analysis was performed to evaluate the predictive value of age, sex, arterial hypertension, and DAs (treatment duration and cumulative dose) as risk factors for valvular fibrosis. It was confirmed that age (odds ratio (OR) 1.07, 95\% CI 1.04-1.10; $P<0.0001)$ and arterial hypertension (OR 2.35; $95 \%$ CI $1.16-4.41 ; P=0.018$ ) significantly elevated the risk of valvular fibrosis. In contrast, gender (OR 1.13; $95 \%$
CI $0.55-2.30 ; P=0.739$ ) and hypopituitarism (OR 1.07 ; $95 \%$ CI $0.39-2.91 ; P=0.899)$ were not associated with an increased valve fibrotic risk. We found a significantly increased risk of valvular fibrosis in both groups of DA-treated patients compared with healthy controls: cabergoline- and bromocriptine-treated patients are 2.27 times (OR 2.27 95\% CI 1.17-4.41; $P=0.016$ ) and 2.66 times (OR 2.66 95\% CI 1.22-5.78; $P=0.014)$ respectively more likely to develop valve fibrosis compared with subjects not exposed to DAs. Naïve prolactinoma patients did not differ from the healthy subjects in respect of their valve fibrosis risk (OR 1.08; 95\% CI 0.49-2.38; $P=0.846$; Fig. 1; Table 5).

We found a strong quadratic relationship between valve fibrosis and treatment duration in both cabergoline- and bromocriptine-treated patients ( $\eta$ coefficients of correlation: 0.773 and 0.865 respectively). A similar nonlinear correlation between fibrosis and cumulative

Table 4 Characteristics of the subjects with clinically relevant regurgitations.

\begin{tabular}{|c|c|c|c|c|c|c|c|c|c|}
\hline \multirow[b]{2}{*}{$\begin{array}{l}\text { Age } \\
\text { (years) }\end{array}$} & \multirow[b]{2}{*}{ Sex } & \multirow[b]{2}{*}{ Group } & \multirow[b]{2}{*}{$\mathbf{A H}^{\mathrm{a}}$} & \multirow[b]{2}{*}{$\begin{array}{l}\text { Hypopi- } \\
\text { tuitarism }\end{array}$} & \multirow[b]{2}{*}{ TD $(\mathrm{m})$} & \multirow[b]{2}{*}{ CD (mg) } & \multicolumn{3}{|c|}{ Affected valves/grade of regurgitation } \\
\hline & & & & & & & Mitral & Aortic & Tricuspid \\
\hline 50 & $\mathrm{~F}$ & Cabergoline & $\mathrm{N}$ & $\mathrm{N}$ & 48 & 96 & Fibrosis (grade 0 ) & $\begin{array}{l}\text { Fibrocalcinosis } \\
\text { (grade 2) }\end{array}$ & Fibrosis (grade 1) \\
\hline 62 & M & Cabergoline & $\mathrm{Y}$ & $\mathrm{N}$ & 96 & 284 & $\begin{array}{l}\text { Fibrocalcinosis } \\
\text { (grade 1) }\end{array}$ & $\begin{array}{l}\text { Fibrocalcinosis } \\
\text { (grade 2) }\end{array}$ & Fibrosis (grade 1) \\
\hline 50 & $\mathrm{~F}$ & Bromocriptine & $\mathrm{N}$ & $\mathrm{N}$ & 240 & 36000 & Fibrosis (grade 2) & Fibrosis (grade 2) & Fibrosis (grade 1 ) \\
\hline 69 & $\mathrm{M}$ & Naïve patient & $\mathrm{Y}$ & $\mathrm{Y}$ & - & - & Fibrosis (grade 1 ) & Fibrosis (grade 0) & Fibrosis (grade 3) \\
\hline
\end{tabular}

$\mathrm{Y}$, yes; $\mathrm{N}, \mathrm{no} . \mathrm{AH}$, arterial hypertension; $\mathrm{TD}$, treatment duration; $\mathrm{CD}$, cumulative dose 


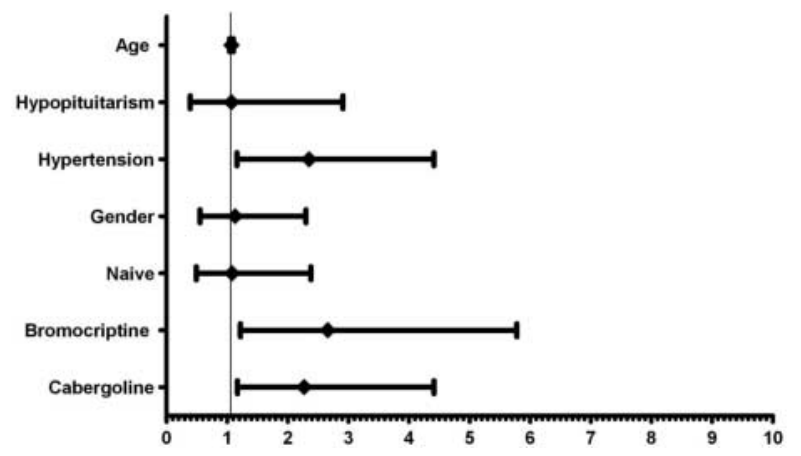

Figure 1 Relative risk for development of subclinical valvular fibrosis in bromocriptine-treated, cabergoline-treated, and medically naïve prolactinoma patients in comparison with healthy subjects.

dose was also observed $(\eta=0.888$ for cabergoline and $\eta=0.896$ for bromocriptine groups). For comparison, the respective Pearson's coefficients were 0.117 , -0.073 and $0.280,0.238$.

\section{Discussion}

Our results demonstrate that the long-term treatment with the ergo-derived DAs cabergoline and bromocriptine in patients with prolactinomas is not associated with clinically relevant cardiac valve regurgitation. On the other hand, we have found an increased prevalence and a significantly elevated risk for development of subclinical valve fibrosis among cabergolineand bromocriptine-treated subjects in comparison with medically naïve patients and healthy controls. Furthermore, fibrosis of more than one valve was twice as common in both groups of DA-treated patients than in de novo patients and healthy controls in contrast to monovalvular involvement, which was equally prevalent in all study groups. Data analysis, however, showed that the valve fibrosis is nonlinearly related to either cabergoline or bromocriptine treatment duration and to the cumulative dose. Quadratic model seems to fit the data best. A clear linear dose and duration dependency of fibrotic valvular disease was found in Parkinsonian patients who are usually treated with approximately tenfold higher doses than the prolactinoma patients $(6,22)$. In contrast, results of the previous studies in prolactinoma patients are controversial, but most of them reported no linear relation between the severity of valvular lesions and cumulative dose (23, 24, $25,26,27,28)$. We could, therefore, suggest that the dose-response relationship may be different in low- and high-dose regimens. Another possible explanation could be that at low doses, valvular fibrosis could develop only in the presence of additional profibrotic factors (genetic predisposition, unknown underlying valvular degenerative disease, hypertension, etc.).
Table 5 Relative risk for the development of subclinical valvular fibrosis in bromocriptine-treated, cabergoline-treated, and medically naïve prolactinoma patients in comparison with healthy subjects.

\begin{tabular}{lcccc}
\hline & & & \multicolumn{2}{c}{$95 \% \mathbf{C l}$} \\
\cline { 4 - 5 } & $\boldsymbol{P}$ & Odds ratio & Lower & Upper \\
\hline Age & 0.000 & 1.070 & 1.040 & 1.100 \\
Hypopituitarism & 0.899 & 1.067 & 0.391 & 2.912 \\
Hypertension & 0.018 & 2.350 & 1.160 & 4.410 \\
Gender & 0.739 & 1.129 & 0.554 & 2.301 \\
Naïve patients & 0.846 & 1.081 & 0.491 & 2.380 \\
Bromocriptine & 0.014 & 2.658 & 1.223 & 5.775 \\
Cabergoline & 0.016 & 2.269 & 1.168 & 4.406 \\
\hline
\end{tabular}

Results from ten observational studies investigating the risk of fibrotic valvulopathy in cabergoline-treated patients have been published to date $(23,24,25,26$, $27,28,29,30,31,32)$. Five of them have shown no relevant findings $(24,25,27,29,30)$. Four trials have demonstrated an increased prevalence of clinically insignificant valvular changes such as mild tricuspid regurgitation $(23,28,32)$, pulmonic regurgitation (32), aortic calcification (28), and an increased mitral tenting area (26). So far, only one study has reported an increased prevalence of moderate tricuspid regurgitation with a positive correlation between cumulative dose and the risk of clinically relevant valvular damage in subjects with prolactinomas taking cabergoline (31). In contrast, evidence-based information about a potential profibrotic effect of bromocriptine is scarce. A possible explanation could be the fact that bromocriptine has been previously incorrectly considered to be an antagonist of HTR2B (33). As opposed to this concept, Tan et al. (22) have demonstrated an elevated dose-dependent risk of FVHD in bromocriptine-treated subjects with Parkinson's disease. In addition, there have been reports in the literature of pleuropulmonary, pericardial, retroperitoneal, and cardiac valve fibrosis in patients on long-term bromocriptine therapy $(10,11$, $12,13,14,15)$. These data are consistent with the recent evidence for partial agonistic activity of bromocriptine on HTR2B (34).

Recruitment of patients on bromocriptine is extremely difficult because cabergoline with its superior efficacy and tolerability has almost completely replaced bromocriptine as a first choice of drug for treatment of prolactinomas. Subjects on bromocriptine therapy have been included in only two studies published so far. In the cross-sectional study of Kars et al. (28), comparisons were made between a group of patients on cabergoline therapy and a combined group of subjects treated with three another DAs with completely different activity on HTR2B: bromocriptine (partial agonist), quinagolide (non-ergoline derivative), and terguride (potent HTR2B antagonist). The study of Bogushevsky et al. (15) has included a separate, but very small from a statistical point of view, sample of bromocriptine-taking subjects $(n=19)$. To our knowledge, our study is the first 
statistically powerful study to investigate the impact of long-term bromocriptine treatment on cardiac valves in patients with prolactinomas. We did not demonstrate significant difference in frequency of clinically relevant regurgitation of any valve between cabergoline-treated, bromocriptine-treated, medically naïve patients and healthy subjects. These results are not unexpected given the fact that the usual doses for treatment of prolactinomas are considerably less than those for Parkinson's disease. The highest cabergoline cumulative dose $(1.32 \mathrm{~g})$ in our study is three times lower than the doses associated with an increased relative risk for FVHD in Parkinson's patients. The hemodynamically significant regurgitations in our patients were even less common than in the general population $(35,36)$. This is not surprising considering the relatively young age of the study participants and exclusion of subjects with severe, uncontrolled, or long-lasting arterial hypertension as well as ischemic heart disease and all other factors with a potential profibrotic action. According to the largest population-based studies, age and hypertension are two of the most important clinical determinants of the valvular regurgitations' prevalence and severity $(35,36,37)$. As a consequence of the restrictive exclusion criteria, only eight of our patients were diagnosed with clinically significant regurgitations. Four $(50 \%)$ of them dropped out after performing the study procedures: three patients who met the exclusion criteria and one patient because of a suspected bicuspid aortic valve. Data of the remaining four patients were analyzed. Although the age, the presence of arterial hypertension, and multivalvular involvement suggest an underlying degenerative valve disease in three of them, there are some contra-arguments. Calcific aortic stenosis and mitral insufficiency are the most typical degenerative valve lesions, whereas we found aortic and tricuspid regurgitations and did not observe any pathological mitral lesions. We could not exclude the drug-induced valvular fibrosis in the last patient, a 50-year-old woman without any potential risk factors for valvulopathy. She has been exposed to a very high cumulative dose (36 g) as a result of 20-year treatment with bromocriptine.

Surprisingly, although none of the investigated subjects were diagnosed with pulmonary hypertension, the systolic and mean arterial pulmonary pressures were significantly higher in the bromocriptine group compared with the other study groups. One recent meta-analysis based on the data from well-designed observational trials has shown an increase in pulmonary artery pressure in pergolide-treated Parkinsonian patients (38). Of note, Colao et al. (31) reported pulmonary hypertension in a substantial proportion of cabergoline-treated subjects with prolactinomas.

Hemodynamically, arterial pulmonary pressure may be elevated by an increase in right ventricular output, pulmonary venous pressure, or pulmonary vascular resistance (PVR). As there was no evidence for the presence of the first two mechanisms in our patients, higher PVR may be presumed. Drug-induced interstitial lung fibrosis and 5-HT-mediated vasoconstriction could be speculatively discussed as probable underlying causes. Such a hypothesis seems possible in the light of recent data supporting the crucial role of HTR1B and HTR2B receptors in the pathogenesis of pulmonary arterial hypertension in humans $(39,40,41)$. Significantly prolonged IVRT in our patients on bromocriptine and even the increased LVM index could also be speculatively explained by underlying interstitial myocardial fibrosis due to 5-HT1b-mediated collagen oversecretion by human cardiac myofibroblasts. As both bromocriptine and cabergoline are potent HTR1B agonists, (33) significantly higher values of these parameters in the bromocriptine group could be explained by the statistically longer treatment duration compared with the cabergoline group. All these mechanisms are hypothetical in the absence of data from prospective studies investigating pulmonary function in patients on long-term DA treatment.

This study has several major advantages. This is the first study with sufficient statistical power to investigate the potential effect of long-term bromocriptine treatment on cardiac valves in patients with prolactinomas. Secondly, the control group consisted of randomly selected healthy subjects without clinical indication for echocardiography. Thus, we avoided the selection bias of some previous studies in which the control groups have been recruited from echocardiographic databases $(25,29)$. In addition, we eliminated the influence of the most important risk factors for development of fibrotic valvulopathy such as advanced age, severe and uncontrolled arterial hypertension, and ischemic heart disease. Finally, special attention was given to the pulmonary hypertension as a potential adverse event in the high-dose DA therapy.

\section{Conclusions}

Long-term treatment with cabergoline and bromocriptine at conventional doses and with duration in accordance to the current guidelines for the management of prolactinomas seems not to be associated with an increased risk of clinically significant valvular heart disease but possible subclinical valvular changes could be expected. Large prospective studies are needed to identify the risk in subjects with invasive macroadenomas who are usually under lifelong high-dose DA treatment. We strongly recommend an echocardiographic examination in patients with prolactinomas before and periodically during therapy with DAs acting as full or partial agonists of 5-hydroxytryptamine 2B receptors (cabergoline and bromocriptine). Based on the recent data about the upregulation of HTR1B and HTR2B receptors in the pathogenesis of pulmonary hypertension, further studies are needed to investigate 
the possible impact of long-term DA treatment on pulmonary arterial pressure. Bromocriptine seems not to be a safe alternative in subjects receiving cabergoline treatment who have preexisting or diagnosed abnormalities, suggesting valvular or interstitial myocardial or pulmonary fibrosis.

\section{Declaration of interest}

The authors declare that there is no conflict of interest that could be perceived as prejudicing the impartiality of the research reported.

\section{Funding}

This work was supported by a grant from the Bulgarian Ministry of Education and Science (contract no. DO02-356/31.12.2008).

\section{References}

1 Pritchett AM, Morrison JF, Edwards WD, Schaff HV, Connolly HM \& Espinosa RE. Valvular heart disease in patients taking pergolide. Mayo Clinic Proceedings 200277 1280-1286. (doi:10.4065/77. 12.1280)

2 Van Camp G, Flamez A, Cosyns B, Goldstein J, Perdaens C \& Schoors D. Heart valvular disease in patients with Parkinson's disease treated with high-dose pergolide. Neurology 200361 859-861.

3 Baseman DG, O'Suilleabhain PE, Reimold SC, Laskar SR, Baseman JG \& Dewey R Jr. Pergolide use in Parkinson disease is associated with cardiac valve regurgitation. Neurology 200463 301-304.

4 Horvath J, Fross RD, Kleiner-Fisman G, Lerch R, Stalder H, Liaudat S, Raskoff WJ, Flachsbart KD, Rakowski H, Pache JC, Burkhard PR \& Lang AE. Severe multivalvular heart disease: a new complication of the ergot derivative dopamine agonists. Movement Disorders 200419 656-662. (doi:10.1002/mds. 20201)

5 Yamamoto M, Uesugi T \& Nakayama T. Dopamine agonists and cardiac valvulopathy in Parkinson disease: a case-control study. Neurology 200667 1225-1229. (doi:10.1212/01.wnl. $0000238508.68593 .1 \mathrm{~d})$

6 Zanettini R, Antonini A, Gatto G, Gentile R, Tesei S \& Pezzoli G. Valvular heart disease and the use of dopamine agonists for Parkinson's disease. New England Journal of Medicine $20073 \mathbf{5 6}$ 39-46. (doi:10.1056/NEJMoa054830)

7 Rothman RB, Baumann MH, Savage JE, Rauser L, McBride A, Hufeisen SJ \& Roth BL. Evidence for possible involvement of 5-HT(2B) receptors in the cardiac valvulopathy associated with fenfluramine and other serotonergic medications. Circulation 2000 102 2836-2841. (doi:10.1161/01.CIR.102.23.2836)

8 Schade R, Andersohn F, Suissa S, Haverkamp W \& Garbe E. Dopamine agonists and the risk of cardiac-valve regurgitation. New England Journal of Medicine 2007356 29-38. (doi:10.1056/ NEJMoa062222)

9 Hofmann C, Penner U, Dorow R, Pertz HH, Jähnichen S, Horowski R, Latté KP, Palla D \& Schurad B. Lisuride, a dopamine receptor agonist with 5-HT2B receptor antagonist properties: absence of cardiac valvulopathy adverse drug reaction reports supports the concept of a crucial role for 5-HT2B receptor agonism in cardiac valvular fibrosis. Clinical Neuropharmacology 200629 80-86. (doi:10.1097/00002826-200603000-00005)

10 Serratrice J, Disdier P, Habib G, Viallet F \& Weiller PJ. Fibrotic valvular heart disease subsequent to bromocriptine treatment. Cardiology in Review $200210334-336$. (doi:10.1097/00045415200211000-00005)
11 Ciubotaru V, Poinsignon Y, Brunet-Bourgin F, Mestassi M \& Rosenbaum D. Severe pleuropericarditis induced by long-term bromocriptin therapy, report of a case and review of the literature. La Revue de Medecine Interne 200425 310-314. (doi:10.1016/j. revmed.2004.01.004)

12 Saura J, Aguilar M \& Alió J. Pleural effusion and constrictive pericarditis secondary to bromocriptine treatment. Neurologia $19916331-333$.

13 Debove P, Simon F, Vaylet F, Renard JL \& L'Her P. Pleuropneumopathy caused by bromocriptine in a patient with Parkinson's disease. Review of the literature apropos of a new case. Annales de Medecine Interne 1998149 167-171.

14 Kains JP, Hardy JC, Chevalier C \& Collier A. Retroperitoneal fibrosis in two patients with Parkinson's disease treated with bromocriptine. Acta Clinica Belgica 199045 306-310.

15 Boguszewski CL, Dos Santos CM, Sakamoto KS, Marini LC, de Souza AM \& Azevedo M. A comparison of cabergoline and bromocriptine on the risk of valvular heart disease in patients with prolactinomas. Pituitary 201215 44-49. (doi:10.1007/s11102011-0339-7)

16 The Seventh Report of the Joint National Committee on Prevention, Detection, Evaluation, and Treatment of High Blood Pressure (JNC 7), U.S. DEPARTMENT OF HEALTH AND HUMAN SERVICES National Institutes of Health, National Heart, Lung, and Blood Institute, National High Blood Pressure Education Program. NIH Publication No. 04-5230; August 2004.

17 Mosteller RD. Simplified calculation of body surface area. New England Journal of Medicine 1987317 1098. (doi:10.1056/ NEJM198710223171717)

18 Zoghbi WA, Enriquez-Sarano M, Foster E, Grayburn PA, Kraft CD, Levine RA, Nihoyannopoulos P, Otto CM, Quinones MA, Rakowski H, Stewart WJ, Waggoner A, Weissman NJ \& American Society of Echocardiography. Recommendations for evaluation of the severity of native valvular regurgitation with two-dimensional and Doppler echocardiography. Journal of the American Society of Echocardiography $2003 \quad 16 \quad 777-802 . \quad$ (doi:10.1016/S08947317(03)00335-3)

19 Lancelotti P, Moura L, Pierard LA, Agricola E, Popescu BA, Tribouilloy C, Hagendorff A, Monin JL, Badano L, Zamorano JL \& on behalf of the European Association of Echocardiography. European Association of Echocardiography recommendations for the assessment of valvular regurgitation. European Journal of Echocardiography 201011 307-332. (doi:10.1093/ejechocard/ jeq031)

20 Chemla D, Castelain V, Provencher S, Humbert M, Simonneau G \& Hervé P. Evaluation of various empirical formulas for estimating mean pulmonary artery pressure by using systolic pulmonary artery pressure in adults. Chest 2009135 760-768. (doi:10. 1378/chest.08-0904)

21 Devereux RB \& Reichek N. Echocardiographic determination of left ventricular mass in man. Anatomic validation of the method. Circulation 197755 613-618. (doi:10.1161/01.CIR. 55.4.613)

22 Tan LC, Ng KK, Au WL, Lee RK, Chan YH \& Tan NC. Bromocriptine use and the risk of valvular heart disease. Movement Disorders 200924 344-349. (doi:10.1002/mds.22228)

23 Nachtigall LB, Valassi E, Lo J, McCarty D, Passeri J, Biller BM, Miller KK, Utz A, Grinspoon S, Lawson EA \& Klibanski A. Gender effects on cardiac valvular function in hyperprolactinaemic patients receiving cabergoline: a retrospective study. Clinical Endocrinology 201072 53-58. (doi:10.1111/j.1365-2265.2009. 03608.x)

24 Lafeber M, Stades AM, Valk GD, Cramer MJ, Teding van Berkhout F \& Zelissen PM. Absence of major fibrotic adverse events in hyperprolactinemic patients treated with cabergoline. European Journal of Endocrinology 2010162 667-675. (doi:10.1530/EJE09-0989)

25 Vallette S, Serri K, Rivera J, Santagata P, Delorme S, Garfield N, Kahtani N, Beauregard H, Aris-Jilwan N, Houde G \& Serri O. 
Long-term cabergoline therapy is not associated with valvular heart disease in patients with prolactinomas. Pituitary 200912 153-157. (doi:10.1007/s11102-008-0134-2)

26 Lancellotti P, Livadariu E, Markov M, Daly AF, Burlacu MC, Betea D, Pierard L \& Beckers A. Cabergoline and the risk of valvular lesions in endocrine disease. European Journal of Endocrinology 2008159 1-5. (doi:10.1530/EJE-08-0213)

27 Herring N, Szmigielski C, Becher H, Karavitaki N \& Wass JA. Valvular heart disease and the use of cabergoline for the treatment of prolactinoma. Clinical Endocrinology $2009 \mathbf{7 0}$ 104-108. (doi:10.1111/j.1365-2265.2008.03458.x)

28 Kars M, Delgado V, Holman ER, Feelders RA, Smit JW, Romijn JA, Bax JJ \& Pereira AM. Aortic valve calcification and mild tricuspid regurgitation but no clinical heart disease after 8 years of dopamine agonist therapy for prolactinoma. Journal of Clinical Endocrinology and Metabolism 200893 3348-3356. (doi:10. 1210/jc.2007-2658)

29 Tan T, Cabrita IZ, Hensman D, Grogono J, Dhillo WS, Baynes KC, Eliahoo J, Meeran K, Robinson S, Nihoyannopoulos P \& Martin NM. Assessment of cardiac valve dysfunction in patients receiving cabergoline treatment for hyperprolactinaemia. Clinical Endocrinology 201073 369-374. (doi:10.1111/j.1365-2265. 2010.03827.x)

30 Bogazzi F, Buralli S, Manetti L, Raffaelli V, Cigni T, Lombardi M, Boresi F, Taddei S, Salvetti A \& Martino E. Treatment with low doses of cabergoline is not associated with increased prevalence of cardiac valve regurgitation in patients with hyperprolactinaemia. International Journal of Clinical Practice 200862 1864-1869. (doi:10.1111/j.1742-1241.2008.01779.x)

31 Colao A, Galderisi M, Di Sarno A, Pardo M, Gaccione M, D’Andrea M, Guerra E, Pivonello R, Lerro G \& Lombardi G. Increased prevalence of tricuspid regurgitation in patients with prolactinomas chronically treated with cabergoline. Journal of Clinical Endocrinology and Metabolism 200893 3777-3784. (doi:10.1210/jc.2007-1403)

32 Wakil A, Rigby AS, Clark AL, Kallvikbacka-Bennett A \& Atkin SL. Low dose cabergoline for hyperprolactinaemia is not associated with clinically significant valvular heart disease. European Journal of Endocrinology 2008159 R11-R14. (doi:10.1530/EJE08-0365)

33 Newman-Tancredi A, Cussac D, Quentric Y, Touzard M, Verrièle L, Carpentier N \& Millan MJ. Differential actions of antiparkinson agents at multiple classes of monoaminergic receptor. III. Agonist and antagonist properties at serotonin, 5-HT(1) and
5-HT(2), receptor subtypes. Journal of Pharmacology and Experimental Therapeutics 2002303 815-822. (doi:10.1124/jpet.102. 039883)

34 Jähnichen S, Horowski R \& Pertz H. Agonism at $5-\mathrm{HT}_{2 \mathrm{~B}}$ receptors is not a class effect of the ergolines. European Journal of Pharmacology 2005513 225-228. (doi:10.1016/j.ejphar.2005.03.010)

35 Singh JP, Evans JC, Levy D, Larson MG, Freed LA, Fuller DL, Lehman B \& Benjamin EJ. Prevalence and clinical determinants of mitral, tricuspid, and aortic regurgitation (the Framingham Heart Study). American Journal of Cardiology 199983 897-902. (doi:10.1016/SO002-9149(98)01064-9)

36 Jones EC, Devereux RB, Roman MJ, Liu JE, Fishman D, Lee ET, Welty TK, Fabsitz RR \& Howard BV. Prevalence and correlates of mitral regurgitation in a population-based sample (the Strong Heart Study). American Journal of Cardiology 200187 298-304. (doi:10.1016/SO002-9149(00)01362-X)

37 Freed LA, Benjamin EJ, Levy D, Larson MG, Evans JC, Fuller DL, Lehman B \& Levine RA. Mitral valve prolapse in the general population: the benign nature of echocardiographic features in the Framingham Heart Study. Journal of the American College of Cardiology 200240 1298-1304. (doi:10.1016/S0735-1097 (02)02161-7)

38 Rasmussen VG, Ostergaard K, Dupont E \& Poulsen SH. The risk of valvular refurgitation in patients with Parkinson's disease treated with dopamine receptor agonists. Movement Disorders 201126 801-806. (doi:10.1002/mds.23470)

39 Launay JM, Hervé P, Peoc'h K, Tournois C, Callebert J, Nebigil CG, Etienne N, Drouet L, Humbert M, Simonneau G \& Maroteaux L. Function of the 5-hydroxytryptamine 2B receptor in pulmonary hypertension. Nature Medicine 20028 1129-1135. (doi:10.1038/ nm764)

40 Königshoff M, Dumitrascu R, Udalov S, Amarie OV, Reiter R, Grimminger F, Seeger W, Schermuly RT \& Eickelberg O. Increased expression of 5-hydroxytryptamine $2 \mathrm{~A} / \mathrm{B}$ receptors in idiopathic pulmonary fibrosis: a rationale for therapeutic intervention. Thorax 201065 949-955. (doi:10.1136/thx.2009.134353)

41 Kaumann AJ \& Levy FO. 5-Hydroxytryptamine receptors in the human cardiovascular system. Pharmacology $\mathcal{E}$ Therapeutics 2006 111 674-706. (doi:10.1016/j.pharmthera.2005.12.004)

Received 9 February 2012

Revised version received 9 April 2012

Accepted 16 April 2012 